\title{
A MODEL TO DECOMPOSE PROPERTY RENTAL MULTIPIERS WITH REGARD TO THE DIVISION BETWEEN LAND AND BUILDING ELEMENTS
}

\author{
prof. S.A. Smolyak \\ Central Economics and Mathematics Institute (CEMI) \\ Russia Academy of Science (RAS) \\ e-mail: smolyak1@yandex.ru
}

\begin{abstract}
We propose a new model for the decomposition of rental multipliers for the property building element which also supports valuation of income-producing real properties based on the principle of stability and an un-orthodox application of discounted cash flow analysis. Having regard to the building/land element analytical split of overall property, the proposed model explicitly accounts for the impact of the value of underlying land on the decomposition of rental multipliers, and doesn't require long-term forecasting of income.
\end{abstract}

Key words: market value, valuation, buildings, income, rental multiplier, land, taxes, ad valorem expenditures, discounting.

JEL Classification: R30, D03, D40

Citation: Smolyak S. A., 2016, A Model to Decompose Property Rental Multipiers with Regard to the Division Between Land and Building Elements, Real Estate Management and Valuation, Vol. 24, No. 1, pp. 51-63.

DOI: $10.1515 /$ remav-2016-0005

\section{Conventional models for rental multipliers}

The market valuation of a building is often performed through a process of direct capitalization, i.e. by multiplying the annual income from the rental use of the building by a rent multiplier (RM). Multipliers can be developed from transactional data on similar buildings, usually for some period preceding the valuation date. However, in the process one must also adjust for the differences between the building being valued and its comparables. To introduce such an adjustment, it is important to know what factors affect the value of the RM and in what way. The associated analysis is usually based on the application of the income approach to the valuation of property. The procedural aspects and effectiveness of such an analysis have been discussed in many research works, among which we can mention books (BROWN 2005; GRIBOVSKY et al., 2003) and research papers tackling the subject of the decomposition of rental multipliers (WINNNICK 1952; AMBROSE \& NOURSE 1993; SiviTANiDES et al. 2001; YISHENG, 2004; CONNER \& LiANG 2005; LEYFER 2006; STROKOV \& STROKOVA, 2011; LEE et al., 2014). Most frequently, rental multipliers related to overall property (i.e. land plus building elements) are subjected to such an analysis - usually accompanied by varieties of regression analysis in an attempt to link variables into which the multipliers have been decomposed with the market. In those occasional instances (e.g. LEYFER 2006; STROKOV \& STROKOVA, 2011) where the overall property is analytically decomposed into its land and building elements for separate treatment, such an analysis is, for the most part, based on limited mathematical transformations involving the wellknown cash-flow discounting formula. Often, such an analysis is constrained by rather rigid assumptions as to the projection period over which a determinate change in income from the property (usually extrapolated by means of an arithmetic or a geometric progression) is assumed - along with 
the terminal (reversionary) value that the property will have at the end of the projection period. A typical model of this kind has been illustrated below.

The primary inputs into the model are: $B$-- annual income from the use of the building (over the first year of the projection period), the income growth rate $i$, the duration of the projection period $T$, and a reversionary or residual value of the building at the end of the period -- $P$. It is assumed that income from the use of the building accrues at the end of each year, while the rate of income growth (i) is less than the discount rate $(R)$.The value of the building at the valuation date $(C)$, at an annual nominal discount rate of $R$, can be determined by the DCF method as follows:

$$
C=\sum_{n=1}^{T} \frac{B(1+i)^{n-1}}{(1+R)^{n}}+\frac{P}{(1+R)^{T}}=\frac{B}{R-i} \times\left[1-\left(\frac{1+i}{1+R}\right)^{T}\right]+\frac{P}{(1+R)^{T}} .
$$

Given this, what if a hypothetical situation arose where $i \geq R$ is not within a range of feasibility? In such a case, it would be appropriate to continue using the building indefinitely. Therefore, any reallife scenario must be such that the rate of growth in income from the use of the building is less than the discount rate. In situations where $T \rightarrow \infty$, formula (1) is transformed into the well-known Gordon growth formula.

To get a final value of the building, we have to make additional assumptions regarding its reversionary value. Examples of these assumptions include the following:

1. Reversionary value is estimated as a proportion or certain fraction (( "gamma") of the "initial" value, i.e. $\mathrm{P}=\quad$ C (LEYFER, 2006),

2. The value of the rent multiplier for year $T$-- $R M_{T}$-- is known,

3. A ratio of rent multipliers at the beginning and termination of the projection period is known -$k=R M_{T} / R M$.

For example, making assumption 1 transforms formula (1) into:

$$
R M=\frac{C}{B}=\frac{1}{R-i} \times\left[1-\left(\frac{1+i}{1+R}\right)^{T}\right] /\left[1-\frac{\gamma}{(1+R)^{T}}\right] .
$$

Should assumption 2 be made, then the reversionary value of the building would amount to $P=$ $R M_{T} \times B(1+i)^{T}$, suggesting the following reduction for formula (1):

$$
R M=\frac{C}{B}=\frac{1}{R-i} \times\left[1-\left(\frac{1+i}{1+R}\right)^{T}\right]+R M_{T}\left(\frac{1+i}{1+R}\right)^{T}
$$

In the UK and U.S., assumptions like these, along with some others, enjoy a wide currency among student valuers and investment analysts (e.g. see textbooks: BROWN 2005; SAYCE, 2006). Because similar formulas in countless different varieties are encountered, it is important to take note of a number of significant attributes of these formulas.

1. They all recognize that the value of subject properties is affected by the income growth rates for these properties. This is a clear advantage of such valuation techniques. It is important, however, to bear in mind that USPAP requirements have to be followed in establishing these rates (THE APPRAISAL FOUNDATION, 2005, Statement on Appraisal Standards 2). USPAP makes it explicit that "revenue growth rate or decline rate assumptions are premised on analysis of supply/demand factors and other economic conditions and trends within the market area of the subject."

2. If the duration of the projection period, which constitutes a structural input into formula (1), is under 10 years, the last term in the formula will account for a significant contribution to the total value of property (up to $90 \%$ ). Therefore, to appraise a building with some accuracy, it will be necessary to estimate the reversionary value with the same accuracy. Thus, a resulting paradox: for us to be able to estimate the market value of a building today, we must be able to assess, with exactly the same accuracy, what its market value will be in, say, 10 years. The situation would not improve were we to operate not with the reversionary value of the building, but rather with the ratio of the reversionary value to the "current" value, or to income as of the date of the reversion, since we would have to be able to assess this relationship just as 
accurately ${ }^{1}$. Therefore, a fairly accurate assessment, downplaying the issues associated with reversionary values, is only possible if one chooses a sufficiently extended projection period, for example, one which coincides with the residual service life of a building. While this will not entirely do away with the issues involved in estimating the reversionary value, a less accurate assessment of the reversion becomes admissible on logical grounds.

3. The derivation of formula (1) is predicated on the assumption that the discount rate will remain unchanged during the projection period, while the income will grow at a constant rate (in other similar models, constant annual increments of income may be assumed). However, such an assumption would only hold in the context of a stable rate of inflation. Moreover, even if the rates of inflation and rates of growth for rental values have been steady and there are grounds to expect them to remain unchanged over the near term, it may be unreasonable to project the same to hold true over the next 10-20 years. It may seem easy to fix this flaw by introducing a time-variable discount rate into the calculations, as well as a rate of growth in rental values. However, the formulas would become much more complex, and the result would heavily depend on the forecasts made by the appraiser.

4. If the projection period is sufficiently long, then it becomes appropriate to consider the physical and functional deterioration of a subject building. It is not very clear how to incorporate this consideration into models of this type (similarly, the same criticism can be levelled against the Gordon formula and many of its modifications).

5. The derivation of formula (1) assumes that neither the length of a projection period, nor the reversionary value of the subject building depends on the characteristics of the underlying land. However, this assumption is not obvious and, as we shall see, may be inappropriate.

\section{Income from building use}

The subject property comprises both the building being valued plus the land on which it is sited (so we shall talk about the "overall property"). It is assumed that the use of the property brings its owner a certain income (e.g., in the form of rent), and such income accrues on account of the building itself, not the land. Thus, if the tenants are provided, for example, with car parking space, it is assumed that such services are included in the building rents. Our objective is to determine the value of an overall property subject to valuation, but in the process, we shall assume the value of the underlying land to be known. So, essentially, the model we shall be developing is a building valuation model. To this end, we will propose models based also on the income approach, but such as do not require long-term forecasting.

So far, we keep mentioning the "income" associated with the use of a building, but have not discussed the concept. At the same time, while using the DCF method, we must consider not only the income (cash receipts, cash inflows) to the owner, but also the associated expenditures (cash outflows). Indeed, even when a space in the building is leased for rent, the landlord has to incur some expenses/outgoings that are not included in the rent. Typically, these costs are minor and they are either ignored or accounted for as a certain percentage of the rent, but it would appear that such costs must generally be considered as their value is significantly dependent on the condition of the building(s). At the same time, it should be noted that the value of property in our example is independent of whether it has been acquired in an equity settlement or with borrowed funds. So, for the purpose of this article, it shall be assumed that the purchase of the property is fully funded by the buyer's equity.

It should be noted as well that the notion of "income" is used in practice to describe a number of disparate economic indicators. Therefore, we will hereinafter opt to use the more neutral-sounding term, "benefits," often encountered in the International Valuation Standards (IVSC, 2007). We will rely on the following two metrics to gauge benefits arising from the use of the building:

1. Gross benefits - revenues to the owner of the building (from the leasing of the premises).

2. Operating benefits $(\mathrm{OB})$-- gross benefits are lessen by deductions for the operating expenses incurred by the owner. However, the operating expenses exclude any depreciation charges or

\footnotetext{
1 The selection by valuers of a projection period of certain, usually shorter, duration is informed by the need to reflect material changes in the market situation towards the end of such period. But such changes would exert their principal pull on the reversionary value of the building.
} 
taxes $^{2}$. This metric is close in its value and composition to EBITDA (Earnings before interest, taxes, depreciation and amortization), but is not identical to it.

Different owners pay taxes at different rates. Therefore, as a means of ensuring the comparability of different properties, appraisers usually make use of either gross or operating benefits. We will use operating benefits in our model. However, operating benefits can only be called "pre-tax" by convention, since some taxes may be reflected among operating cost components (e.g. in the US, OASDI and Medicare contributions, levied in accordance with the Federal Insurance Contributions Act). This, however, fully accords with appraisal practice, where "pre-tax" qualification only applies to cash flows and operating benefits before income tax, while cash flows and performance indicators prior to the payment of other taxes are generally of minor interest.

Unfortunately, it would only be possible to develop a relatively simple and practically applicable model for the valuation of buildings if the process of income generation from the use of the buildings were described in continuous time. Accordingly, the rates of change in economic performance and the discount rates which we will be discussing below shall be continuous, rather than annual rates. So if we say that such and such a metric is growing at rate $z$, we mean that over a small increment of time, $d t$, it will have grown by $100 z d t \%$ or have sustained a $(1+z d t)$ time increase, while its growth over a year would then amount to $e^{z}$ times, and over $T$ years -- to $e^{z T}$ times. The relationship between the continuous $(z)$ and annual $(Z)$ growth rates (expressed as decimals and similarly "dimensioned", e.g. as reflecting a rate of change per annum) is represented by the following: $Z=e^{z}-1, z=\ln (1+Z)$. Similarly, we will use a continuous discount rate $r$, which is linked to the annualized rate according to the well-known formulas: $R=e^{r}-1, r=\ln (1+R)$. Thus, the income or expense incurred at time $t$, is discounted to its present value estimate at time 0 using a discounting factor of $e^{-r t}$. If the point in time $t$ is sufficiently close to point 0 , the discounting factor can be approximated as $1-r t$.

Since the process of benefit generation by the building is considered in continuous time, we will assume as its defining characteristic a rate ("intensity") of OBs generation, i.e. the size of OBs produced during an incremental unit of time. Therefore, if such a rate at a certain date (for example, the valuation date) is equal to $B$ (say, dimensioned in currency units per annum), then over an incremental interval of time, $d t$, the operating income accruing to the owner of the building will amount to $B d t$. Further, when discussing a rent multiplier, we will assume it is calculated as a ratio of the value of the property (building element) to the rate of operating benefits generated as of the date in question.

Over time the OBs rate associated with the building sustains a change influenced by a number of factors, among which (with real property improvements being a class in long-term depreciable tangible capital stock) obvious analytical significance is carried by factors related to the nominal value of money and obsolescence-related issues. Thus, we would consider the impact of the following on the OB rates:

1. Inflation. At times when prices for goods, labor and services in the country generally increase, the rents which reflect the value of the occupancy of a building over a unit of time (or the value of the right to use a building over a unit of time) also appreciate. The need to incorporate the rental rate growth into the property valuation process is well supported in a number of sources, e.g. (SAYCE et al., 2006). It is important not to lose sight of the fact that the growth rate of prices for certain goods and services may vary for different sorts of goods and deviate from the rate of overall inflation, which reflects the average rate of price growth in the country. It follows, as well, that the growth rate in gross benefits will not in general be equal to the general inflation rate.

2. Physical deterioration. Buildings age over time. Therefore, the owner has to incur larger and larger expenses to provide for building maintenance and repairs. This subject is also explored in reference source [4]. The overall result is that the owner's costs keep rising while his net benefits are reduced.

3. Functional obsolescence. Over the useful life of the subject property, other newer buildings commissioned by investors become available, supplying occupants with a wider range of

\footnotetext{
2 Another exclusion has already been mentioned in connection with the mortgages taken out to acquire the property: interest and repayments on mortgage loans are similarly disregarded in the calculations of operating benefits (instead, being allocated to the main activities of the building owner rather than activities associated with the use of the building).
} 
services (amenities). Such buildings may be more attractive to some tenants who occupy space in the subject building or in similar properties. Faced with such a situation, the building owner is compelled to reduce his rental expectations somewhat and, hence, sacrifice a part of his income to ensure that the space in his building continues to be leased at full capacity.

The nature of the effects of these three factors on the owner's benefits varies substantially. Changes in market prices affect the building owner's income almost immediately. The effect of physical deterioration unfolds gradually, expressing itself in miniscule cost increments barely discernable over a short term. Functional obsolescence is usually absent in un-outmoded buildings, becoming discernable only after the most recently designed buildings hit the market, offering their occupants up-to-date amenities. On balance, the resulting effect over the lifetime of the building may produce an average rate of change for OBs generated by the building that is less than the rate of general inflation, and that sometimes even shifts to negative territory.

\section{The value of land as a factor defining the limit on the effective use of the buildings}

As already noted, a subject building forms an element of the overall property comprising both the building and the land on which it is situated (allowing for all the necessary environmental amenities, for example, green spaces and ground services on the building site). We shall assume the value of land as at the date of valuation, $L$, to be a known variable. In addition, it will be further assumed that the rate of change in the value of land $j$ is known at the valuation date (it can be estimated by analyzing trends in the unit value of acreage for similar plots). In this section, we shall not consider taxes payable by the building owner, and shall characterize the benefits received by the OBs rate.

Prior to the valuation date, the subject building could have been put to an arbitrary use, but its valuation should be predicated upon the highest and best use that can be achieved in the future (THE APPRAISAL FOUNDATION, 2006; IVSC, 2007). Knowing this use (which often coincides with the existing use), the valuer can estimate rate $B$ at which the benefits $(\mathrm{OB})$ are generated by the building.

The value of land generally increases over time. However, the respective growth rate $(j)$ cannot exceed the discount rate. Indeed, if it were otherwise, one might acquire land without caring to put it to any productive use and re-sell it after a certain holding period (at a higher price); one would have, thereby, generated a return at least commensurate with alternative highest and best investment opportunities. However, opportunity for earning such superior returns on similar speculation is not borne out by customary business practice.

We assume that the subject property is one of the properties exchanged on the (real or virtual) market where properties similar to it are also available (properties which are generally characterized by different values for $L$ and $B$ ). Among the buildings offered on this market may be ones which have "no value". Their use, whatever it is, would be impracticable (inefficient); however, they may be purchased for the sake of the underlying land. Let us explore how to "draw the line" separating the buildings "which are worth something" from those which are "of no value".

To do this, let us first note that even similar buildings situated on similar land may produce incomes of different magnitudes. One of the reasons for that may lie in the age difference of the buildings. Even given the same level of "amenities" (and, therefore, the same level of rent), older buildings typically entail higher maintenance and repair costs. Quite often older buildings are also less "comfortable" than newer ones built to modern design and providing their occupants with a wider range of facilities and amenities. In such instances, the rental rates and, hence, the owner's (lessor's) income from older buildings happens to be lower.

At what "critical value" of OBs does the value of the buildings go down to zero? It may seem that as long as a building generates at least some income, its value will remain positive, such that the "critical value" threshold will also equal zero. However, such a view is erroneous. The fact of the matter is that the magnitude of OBs generated by a building does not fully characterize the efficiency of its use over a given interval of time, because it fails to reflect the owner's capital gains or foregone income. The reason is that a part of the building owner's capital is also tied up in the underlying land, the value of which may increase over time. Thus, even though the building may produce zero or even negative benefits over some periods, the owner's capital may be augmented by the rising value of the land. From this it follows that the value of the land must somehow affect the most effective timing for the termination of building use (i.e., the time for selling the overall property at the price of the land). To identify how this effect is exerted, the following arguments are presented. 
Consider an overall property comprising a building and the underlying land at a moment in time when selling it becomes the most effective strategy to pursue. Obviously, the value of the building would approach zero at this point, and the value of the overall property would equal the value of the land $L$.

Let us consider what would happen if the sale of the property were postponed for an incrementally brief period of time $d t$. For the purpose of simplicity, we shall assume that there is no income/profit tax.

The use of the building beyond this $d t$ period would bring its owner net operating benefits $B d t$. Moreover, the value of the underlying land would change over the period. Let $j$ be the continuous rate of change in the value of the underlying land as of the valuation date (determinable through the analysis of unit market price levels for comparable parcels of land). Then the value of land by the end of period $d t$ will have grown by $(1+j d t)$ and have reached the magnitude of $(1+j d t) L$, while the value of the building remains at zero. Consequently, the overall property could then be sold at the price of the land $(1+j d t) L$. In this case, the net discounted income from the use of the building over the period $d t$ and its subsequent resale will amount to $\frac{B d t+(1+j d t) L}{1+r d t}$, where $r$ is a continuous discount rate reflecting returns on alternative most effective investment opportunities. Having considered, per the stipulation, that the sale of property as of the valuation date, rather than after the lapse of period $d t$, is to be viewed as the most efficient strategy, the following condition obtains: $\frac{B d t+(1+j d t) L}{1+r d t} \leq L$, from which it follows that $B \leq(r-j) L$. As has been demonstrated above, $r-j>0$. Thus, the value of a building remains positive as long as the rate of operating benefits from its use exceeds $(r-j) L$ and goes down to zero when this rate becomes level with $(r-j) L$ :

$$
B=(r-j) L
$$

Therefore, by comparing otherwise similar buildings differing only in terms of their location on land parcels of different values, one can see that the higher the land value, the shorter the economically justifiable lifetime of the building.

Let us therefore introduce an index of the Payback Period for Land $(P P L)$ - i.e. the ratio, $p=L / B$, which relates the value of the land to the rate of OBs generated by the building. The foregoing consideration demonstrates that in a case when PPL exceeds $1 /(r-j)$, the continuation of building use for its intended purpose may become economically inefficient, and its value goes down to zero. This implies that the value of a building, and, hence, the rent multiplier $R M=C / B$, are somehow dependent on PPL.

\section{The principle of stable dependencies}

The application of the income capitalization approach to valuing buildings presupposes that the value of rent multipliers is nearly the same for all the buildings that belong to the same category (similar buildings) and remains reasonably stable over time. The technique described below is also based on similar assumptions. However, as can be seen from the above arguments, rent multipliers are expected to differ for buildings with different PPLs. Therefore, a more accurate assumption would be that they are somehow dependent on the value of PPLs, but this dependence itself is stable, i.e. timeinvariant, at least over shorter intervals of time near the valuation date.

Appraisal practice commonly relies on a similar assumption regarding the stability of value dependency on its determinant factors. In fact, it is the stability of these functional relationships which permits the transactional data recorded at some points in time to be applied to establishing the value of properties at other proximate, points in time. We can provide a number of examples of this.

In assessing buildings for taxation purposes many assessors use mathematical models of the following form: $C=a_{0} X_{1}^{a_{1}} X_{2}^{a_{2}} \ldots$, where $X_{1}, X_{2}, \ldots$-- are the attributes of a building, and $a_{0}, a_{1}, a_{2}, \ldots$-are the coefficients reflecting the effect of relevant factors on the value of the building (IAAO, 2003, vide Sec. 3.2.2.2). Note that the coefficients $a_{0}, a_{1}, a_{2}, \ldots$ are determined by appraisers based on the prices of transactions involving similar buildings. But the related estimates rely not on cross-sectional sales data gathered at the valuation date, but on time-divergent data from some retrospective period usually transacted within one year preceding the assessment date. If, after the passage of a subsequent year, the same building has to be re-assessed, the estimates are repeated -- but with reliance on data from transactions completed over the following year. The impact of inflation in the interim is reflected in a change in the $a_{0}$ coefficient, while a correctly specified model would have the $a_{1}, a_{2}, \ldots$ coefficients, reflecting the influence of the individual characteristics of the buildings, only slightly altered over the 
year. It is this circumstance which allows the constructed model to apply at the assessment date, even though it was developed on the basis of earlier data. We shall refer to models (dependencies) of this type as "stable".

The stability of a functional relationship relied upon by the appraiser should either be stated as a particular assumption, or validated by market data from different moments in time. The model proposed below is essentially predicated on the stable dependencies principle.

\section{Model for the rental multiplier}

It will be recalled that we are considering a market in which similar buildings, generating benefits of a different magnitude and situated on land of varying value, are being exchanged. Now, we specify an incrementally brief span of time $d t$ (e.g., a month), commencing from the valuation date, and make the following assumptions for all the properties under consideration during this period of time:

1. that the value of the underlying land is growing at one and the same (known) rate $j$, less than the discount rate,

2. that the rate of OBs generated by the use of each building is growing at one and the same (known) rate $i$, less than the discount rate,

3. that their rent multiplier is dependent on the Payback Period for Land $(p)$, where the corresponding dependency is deemed smooth ${ }^{3}$ and stable. This means that a functional dependence of the form $R M=f(p)$ can be justifiably assumed to hold both as at the valuation date and for the dates in proximity thereto, although the exact structural form of the $f$ function is so far unknown.

It turns out that these assumptions ${ }^{4}$ are sufficient for identifying the unknown function $f$ and valuing a subject building. The method which would be used for arriving at the solution is, in many ways, similar to the one we proposed in (SMOLYAK, 2008; SMOLYAK, 2012) for estimating Percent Good Factors when assessing depreciation in elements of factories and equipment.

Thus, for all buildings on the market at the valuation date and near that date within a brief increment of time, $d t$, we presume that one and the same relationship holds between the building value $(C)$, on the one hand, and the rate of generated OBs $(B)$ and the value of the land $(L)$, on the other:

$$
C=B f(p)=B f\left(\frac{L}{B}\right)
$$

Let us assume that the use of any one of such buildings over a brief interval of time, $d t$, is economically justifiable. Let us specify what the new values for economic attributes $C, B$ and $L$ will be at the end of this period - with these new values being denoted by the diacritical mark (tilda) placed over the respective letter ( $)$. These "future" values for the building and the land, $\tilde{C}$ and $\tilde{L}$, can be deduced from the following considerations. During the period $d t$ the rate of OBs generated by the building will have changed by $(1+i d t)$ times, while the value of the land will have changed by a factor of $(1+j d t)$, thus:

$$
\tilde{B}=(1+i d t) B, \quad \tilde{L}=(1+j d t) L, \quad \tilde{p}=\frac{\tilde{L}}{\tilde{B}}=\frac{1+j d t}{1+i d t} p \approx p+(j-i) p d t .
$$

Incidentally, this shows that the continuous growth rate for PPL is equal to $j-i$, and, as observed at the conclusion of Section 3, this rate is positive.

The value of the building after the interval $d t$ has elapsed, in this case, (with an accuracy up to infinitesimals of a higher order) is:

\footnotetext{
3 In mathematical analysis, a function which is continuous and differentiable at every point is called smooth. Dependencies between economic indicators are usually of a smooth functional variety.

4 These assumptions, inter alia, suggest a more precise specification for the range of "similar buildings" traded on the property market in question. Consonant with such assumptions, similar buildings are regarded to be those buildings which are characterized by one and the same most rational use and are identical in terms of land value growth rates, as well as operating benefit growth rates.

5 The approximate equality sign $\approx$ is hereinafter used in situations where the corresponding expressions differ by a small margin compared to the length of the $d t$ time period (i.e. by a margin of higher-order infinitesimals).
} 


$$
\tilde{C} \approx(1+i d t) B f(p+(j-i) p d t) \approx B f(p)+i B f(p) d t+B f^{\prime}(p)(j-i) p d t
$$

On the other hand, the value of the property at the valuation date can be estimated using the DCF method in its alternative form as stated below:

The value of overall property at the valuation date is equal to the sum of operating benefits produced by the use of the property over the incrementally short period of time $d t$ and the value of the property at the end of this period - discounted back to the valuation date.

In applying this DCF application, it should be noted that:

- the value of the overall property at the valuation date is equal to the sum of the values for the building and the underlying land $(C+L)$,

- the value of the same property at the end of the period is equal to $\tilde{C}+\tilde{L}$,

- operating benefits arising from the use of the building over the period $d t$ constitute a small amount $B d t$ and with an accuracy up to infinitesimals of a higher order can be attributed to occurring as at the valuation date,

- the benefits are discounted at a nominal pre-tax rate $r$, which we assume to be known.

In this case, the DCF framework provides:

$$
C+L \approx B d t+(1-r d t)(\tilde{C}+\tilde{L}) .
$$

Relying on formulas (3), (4), and (5), we can also deduce from this (likewise with an accuracy to within a higher order of infinitesimals):

$$
\begin{gathered}
B f(p)+L \approx B d t+ \\
+(1-r d t)\left[B f(p)+i B f(p) d t+B f^{\prime}(p)(j-i) p d t+(1+j d t) L\right] \approx \\
\approx B f(p)+L+\left\{B-(r-j) L-(r-i) B f(p)+B f^{\prime}(p)(j-i) p\right\} d t .
\end{gathered}
$$

It is easy to see that this equality will only hold if the expression within the curly brackets equals zero. Substituting $B p$ for $L$, it follows that the $f$-function must satisfy the following equation:

$$
(j-i) p f^{\prime}(p)-(r-i) f(p)+1-(r-j) p=0 .
$$

The resulting equation holds true, however, only for those buildings whose intended use is economically feasible as at the valuation date.

Solutions to (7) will vary depending on the particular relationship holding between growth rates for OBs ( $i$ ) and growth rates for the value of land (j). Three cases are possible here.

Case 1. $i<j$. In Section 3 we concluded that the PPL value for such buildings -- the ratio of the value of underlying land to the rate of OBs generated by the building -- should not exceed the threshold level of $1 /(r-j)$. It appears that, given $i<j$, the same conclusion can be supported on the basis of the model developed.

Indeed, consider a building in our market, the intended use of which is not economically justifiable. Then the value of the corresponding property would be greater than the discounted sum of the benefits from its use arising over the $d t$ period and the value of the property at the end of that period. In other words, the approximate equality (6) would transform itself into an approximate inequality:

$$
C+L \gtrsim \operatorname{Bdt}+(1-r d t)(\tilde{C}+\tilde{L})
$$

Note that the value of such a building as at the valuation date is zero, and it will remain at zero at the end of the period, such that $C=\tilde{C}=0$. In addition, $\widetilde{L}=(1+j d t) L$, and, consequently, this inequality takes the following form:

$$
L \gtrsim \mathrm{Bdt}+(1-r d t)(1+j d t) L \approx L+B d t-L(r-j) d t
$$

It is easy to see that this inequality would only be satisfied if $L(r-j) \geq B$, i.e. given that $L / B \geq 1 /(r$ $j)$. Thus, if the Payback Period for Land (PPL) exceeds $s=1 /(r-j)$, then the value of the building goes down to zero, otherwise function $f$ which is under investigation satisfies equation (7). But the 
functional dependence of the value of the building on $B$ and $L$ is continuous, so a solution to (7) must go down to zero for all the buildings for which $L / B=s$ :

$$
f(s)=0 \text {. }
$$

Such a solution to equation (7) subject to the boundary condition (8) may be obtained according to customary methods, and is as follows:

$$
R M=f(p)=\frac{1}{r-i}\left\{1-\frac{\alpha}{\alpha-1}\left(\frac{p}{s}\right)+\frac{1}{\alpha-1}\left(\frac{p}{s}\right)^{\alpha}\right\}
$$

where

$$
s=\frac{1}{r-j} ; \quad \alpha=\frac{r-i}{j-i}
$$

This leads to the following formula for the value of a building:

$$
C=B f(p)=\frac{B}{r-i}\left\{1-\frac{\alpha}{\alpha-1}\left(\frac{L}{B s}\right)+\frac{1}{\alpha-1}\left(\frac{L}{B s}\right)^{\alpha}\right\} \text {. }
$$

We have thus deduced the desired formulas for the rent multiplier and the value of a building. A detailed examination of the rent multiplier formula shows that it differs from the Gordon formula (in continuous time) by the presence of a correction factor reflecting the impact of PPL. Note that in the given case, $\quad>1$, the dependence of $R M$ on PPL will almost be linear at small values of PPLs.

Naturally, this formula is valid only when $p \leq s$, since the values for the building and rent multiplier disappear when $p \geq s$. It is interesting to note that, at $p=s$, not only does the value of the rent multiplier function go down to zero, but also that of its derivative with respect to $p$. This means that the graph line plotting the dependency of $R M$ on PPL becomes tangent to the $\mathrm{x}$-axis at $p=s$.

The resulting dependencies of the rent multiplier on PPL flowing from (9), given the discount rate of $13.5 \%$ per annum, an annual growth rate for the value of land of $7 \%$, and annual growth rates for OBs of $3 \%$ and $5 \%$, are plotted in Figure 1. Figure 2 plots similar dependencies given the annual growth rate for OBs of $3 \%$ and annual growth rates for the value of land of $4 \%, 7 \%$ and $9 \%$.

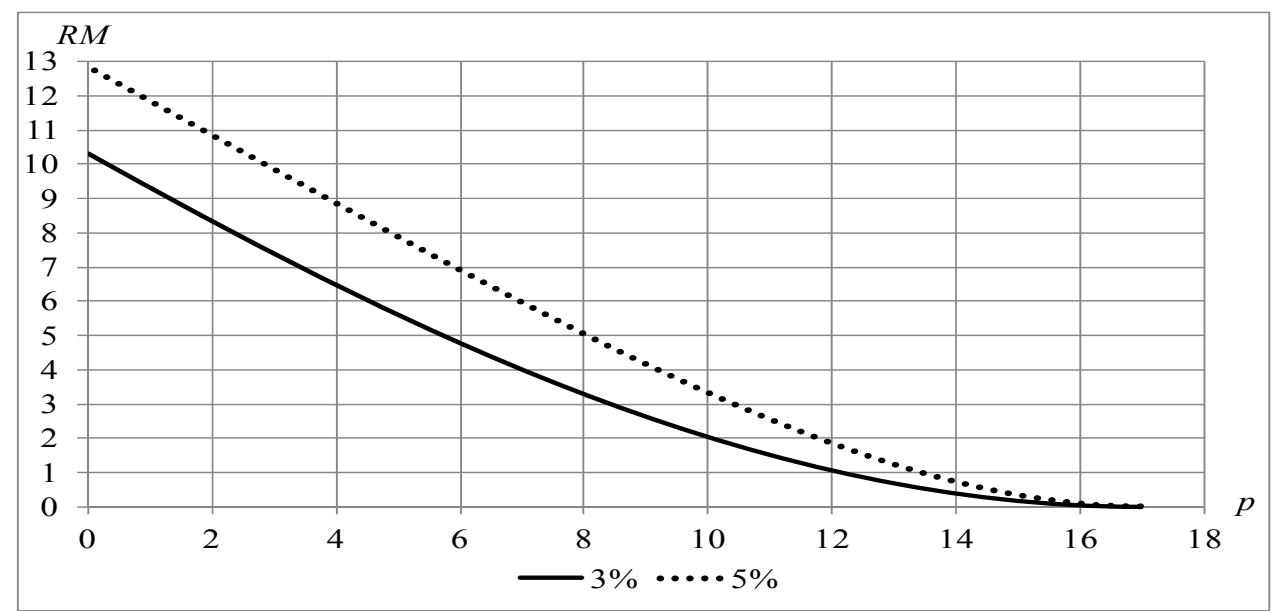

Fig. 1. The dependence of the rent multiplier on PPL for different OBs growth rates. Source: own study.

Case 2. $i=j$. Here, the equation (7) would assume the following form:

$$
-(r-i) f(p)+1-(r-i) p=0
$$

from which it immediately follows that: 


$$
R M=f(p)=\frac{1}{r-i}-p, \quad C=B f(p)=\frac{B}{r-i}-L
$$

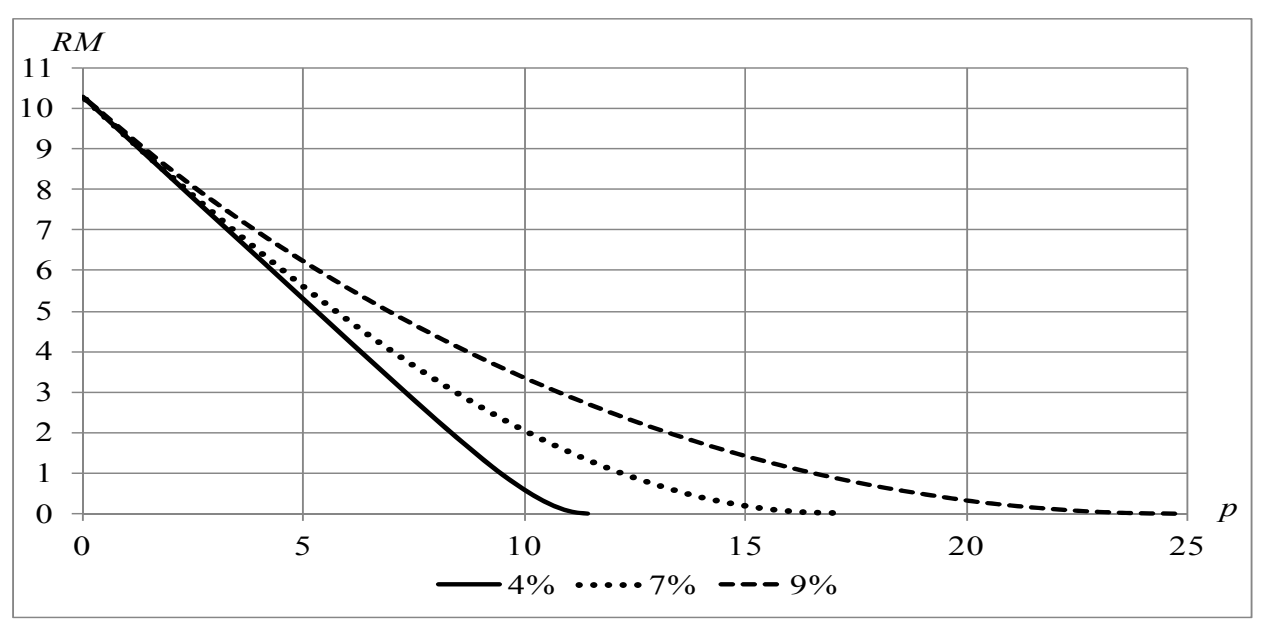

Fig. 2. The dependence of the rent multiplier on $P P L$ for different land value growth rates. Source: own study.

Resulting in the value of overall property of $c+L=\frac{B}{r-i}$, which fully accords with the well-known Gordon formula approach. Note that the formulas obtained are only valid to the extent they return a non-negative value for the building. As can easily be seen, this would only be possible where PPL does not exceed $1 /(r-i)$. Otherwise, the value of the building is zero.

Case 3. $i>j$. It may seem that solutions in this range can also be described by formulas (9), (10), and (11), however this is not the case. The reason is that, according to formula (10), the value of then turns negative, resulting in discontinuities in function (9) ( $p=0$ is the breakpoint locus). A detailed analysis reveals that the only continuous solution to Equation (7) is provided by the same function, i.e. $f(p)=1 /(r-i)-p$, as for Case 2 . Thus, in this case the value of a building will also be zero when $p>1 /(r-i)$, and be represented by Formula (12) in the remaining range.

These findings call for a few important comments.

1. It becomes obvious that the relationship between the market value of a building and the income derivable from it (in other words, the specifications for a rental multiplier) is far from simple: the formulas also include terms for the land value and the rate of growth in land value.

2. We have already mentioned several papers analyzing the specification for rent multipliers. Formulas proposed in those papers are based on assumptions regarding trends in the income to be generated by the use of the property and its reversionary value at the end of the projection period. Our model also assumes that the net income grows at a constant rate, but it involves a projection period of brief duration, while market information about the value of the underlying land and the growth rate in land value over the near future takes the place of hypothetical assumptions regarding the reversionary value of a building. In such a setting, the need does not arise for long-term forecasting of the nominal discount rates and inflation rates, or for introducing assumptions about the constancy of these rates over the entire projection period.

3. The model developed ignores taxes. Essentially, this is equivalent to making an unrealistic assumption about the absence of taxes, although, as envisaged in the valuation standards (IVSC, 2007), this is compensated by the use of a pre-tax discount rate. However, strictly speaking, the amount of operating benefits cannot be referred to as "pre-tax" as the OBs estimate already accounts for some tax-related expenses (e.g., the property tax, as well as OASDI and Medicare contributions in the U.S). In our defense, we can say that appraisal literature conventionally uses the "pre-tax" label to refer to cash flows and other performance indicators developed on a "before income tax only" basis.

4. As can be seen from formulas (9) and (10), the value of the buildings depends not on the parameters $r, i$ and $j$ themselves, but rather on the differences $j-i, r-j$ and $r-i$. The first of these differences, as has been shown above, reflects the rate of growth for PPL; the second, the loss incurred from having invested capital tied up in land to be subsequently resold rather than in 
the best alternative investments available; and the third difference, representing the sum of the first two. Since general inflation in the country affects $r, i$ and $j$ in roughly the same way, the change in inflation rates should not greatly affect the value of the rent multiplier.

5. While the model developed is deterministic, it makes it possible to account for some of the risk factors. Thus, if the use of a building involves the renting out of space, the landlord assumes the vacancy risk (in the interval between the departure of one tenant and the occupancy by another), as well as the risk of the loss of rent (when a tenant moves out without having settled with the landlord). These risks can be taken into account by reducing gross benefits by appropriate adjustment factors ${ }^{6}$.

\section{Some illustrative examples on using the model}

Below are several examples to illustrate the potential applicability of formulas (9), (10), and (11) (all figures used are for illustration purposes only). In these examples, the monetary values are expressed in notional currency units, and the annual discount rate $(R)$ is assumed to be $13.5 \%$, such that the continuous rate is equal to $r=\ln (1+R)=\ln 1.135=0.1266$.

Example 1. The value of land is 120 , the growth rate in land value -- $7 \%$ per annum, the operating income from the use of the building (at its annual rate, expressed in prices effective as at the valuation date) -60 , and the growth rate for the operating income $-3 \%$ per annum.

First off, we have to calculate the immediate inputs: $j=\ln (1.07)=0.0677, i=\ln (1.03)=0.0296, r-j=0.1266$ $0.0677=0.0381, j-I=0.0677-0.0296=0.0381, s=1 / 0.0381=16.96, r-I=0.1266-0.0296=0.0971$, $p=L / B=120 / 60=2.0, \alpha=(r-i) /(j-i)=0.0971 / 0.0381=2.548$.

Then:

$$
\begin{gathered}
R M=\frac{1}{0.0971}\left[1-\frac{2.548}{1.548} \times \frac{2.0}{16.96}+\frac{1}{1.548}\left(\frac{2.0}{16.96}\right)^{2.548}\right]=8.33 \\
C=B \cdot R M=60 \times 8.330=500
\end{gathered} ;
$$

As a result, the value of the overall property at the valuation date amounts to $500+120=620$.

Example 2. In contrast to Example 1, the value of the land is assumed to be twice as high -- 240. In this case: $p=L / B=240 / 60=4.0$,

$$
\begin{aligned}
& R M=\frac{1}{0.0971}\left[1-\frac{2.548}{1.548} \times \frac{4.0}{16.96}+\frac{1}{1.548}\left(\frac{4.0}{16.96}\right)^{2.548}\right]=6.47 \\
& C=B \cdot R M=60 \times 6.47=388 .
\end{aligned}
$$

Thus, the value of the property (the building plus the land) will be $388+240=628$.

Note that the same value for the rent multiplier would have been obtained if the amount of the benefits in Example 1 were to be reduced by half (that is, having assumed $B=30$ ). However, the value of the building in this situation would also be halved - 194 .

Example 3. Assume that, in contrast to the specifications in Example 2, the growth rate in the value of the land is higher -- at $10 \%$ per annum. Repeating the same calculations we obtain: $R M=7.31, C=439$. As can be seen, such a change in inputs causes only a slight difference in the results.

Example 4. Let us find out what effect a possible inaccuracy in establishing the OB growth rates may have on the valuation presented in Example 1. Suppose, for example, that the growth rate is set not at $3 \%$, but at $5 \%$ per annum. Recalculating the terms in formula (9) yields the following: $R M=10.85, C=$ 651. The differences between the two examples are substantial.

Example 5. Let us establish the extent of influence a wrongly estimated discount rate may have on the valuation result in Example 1. Suppose, for example, the rate not to be $13.5 \%$, but $15 \%$. Recalculating the terms in Formula (11) indicates that: $R M=7.09, C=425$. Thus, variations in the discount rate may have a rather strong effect on the valuation results.

\footnotetext{
${ }^{6}$ Adjustments for underutilization of rental space and under-collection of rents should also be considered, even when all the space in the building is fully occupied year-round, and no rents under-collected over the past year. This would help account for the risk of respective losses going forward.
} 


\section{Conclusions}

Empirical evidence shows the market value of a building may depend on the value of the land on which it is situated. The fact of the matter is that the value of the underlying land sets the conditions for the marginal level of net benefits, which determine whether to continue using the building, or to demolish it and dispose of it on the market at the price of the underlying land value. At the same time, as the building ages, the benefits it generates decline relative to the value of the land. Thus, the impact of the land value is in some sense indirect -- it affects the length of the period during which a building can be used efficiently, i.e. the period during which the owner receives net benefits from its use, and as a consequence -- affects the value of the building, i.e. the amount of the discounted benefits from building use over this period. The above relationships can be captured as presented -- via a simple mathematical rent multiplier model, which do not require cash flow forecasting.

This model can be used not only for purposes of estimating the value of buildings on the basis of income arising from their use, but also for solving inverse problems -- assessing market rents for buildings, the value of which is a known item of data. However, practical applications of this model would call for a number of elaborations to account for the impact of property taxes and other advalorem expenses, as well as treating the matter of how to extract needed data from the market for use as parameter inputs to the model. These matters are being addressed by the author in extensions to the proposed model. Another extension of the model, which the author hopes to publish in a forthcoming paper [in REMV], is its use in solving some problems of estimating optimal economic service lives of the buildings.

\section{Acknowledgements}

The presentpaper has been prepared under the sponsorship of a grant from the Appraisal Research Foundation (TARF). The author gratefully acknowledges the editorial assistance that he received from Dr. Michael Milgrim, for many years the editor of International Valuation Standards, and from Andrey Artemenkov, MRICS. Without the assistance and support of these parties, it is unlikely that the paper could have been completed. Prof. Georgiy Mikerin and Mr. Igor Artemenkov, FRICS, have also, from the outset, given the author much appreciated encouragement in developing the ideas set forth in this paper.

\section{References}

AMBROSE, B. \& NOURSE H., 1993, Factors Influencing Capitalization Rates, Journal of Real Estate Research 8: 221-237.

Brown, R. G., 2005, Private Real Estate Investment: Data analysis and decision-making, Elsevier Academic Press, pp. 82-90.

CONNER P., LIANG Y., 2005, Income and Cap rate effects on property Appreciation, The Journal of Portfolio Management, Fall Special Issue.

Gribovsky S. V., IVANOVA E. N., Lvov D. S., Medvedeva O. E., 2003, Real Estate Valuation, Interreklama Publishers, Moscow, (in Russian).

IVSC, 2007, The International Valuation Standards 2007, The International Valuation Standards Council (IVSC). London.

IAAO, 2003, The Standard on Automated Valuation Models, Approved in September 2003. www.iaao.org

KAMKE E., 1948, Differentialgleichungen, Lösungsmetoden und Lösungen, Band II, Partielle Differentialgleichungen erster Ordnung für eine gesuchte Funktion, Academische Verlagsgesellschaft, Leipzig, (in German).

LEE, H. S., CORGEL, J. B., \&SHIN, S., 2014, Estimating net operating income growth for modeling U.S. apartment property capitalization rates, Journal of Real Estate Portfolio Management, 20(1), 67-78. Available online at: http://scholarship.sha.cornell.edu/articles/578/.

LEYFER L. A., 2006, Direct capitalization method. Generalized Inwood Model, in Voprosy Otsenki, №3, pp. 15-20 (the article is also available online at http://www.labrate.ru/leifer/lev_leifer_articlemodel_inwood.htm), (in Russian).

SAyce S., Smith J., CoOPER R., VenMore-Roland P., 2006, Real Estate Appraisal: From Value to Worth, Blackwell Publishing Ltd.

Sivitanides P., SOUthaRd J., TORTO R., WheAtON W., 2001, The Determinants of Appraisal-Based Capitalization Rates. Torto Wheaton Research Inc. Research paper, http://recounsel.net/Determinants_of_Appraisal_Based_Cap_Rates.pdf, (Accessed 20/10/2015). 
SMOLYAK S.A, 2008, Problems and Paradoxes in the Valuation of Machinery and Equipment, RIO MAOC, Moscow, (in Russian).

SMOLYAK S.A., 2012, Models for Estimating Depreciation in Plants, Machinery, and Equipment: Analysis and Proposals, Journal of Property Tax Assessment \& Administration, Volume 9, Issue 3, 2012. pp. 47-86.

Strokov A.V., STROKOVA D.V., 2011, Capitalization Rate and the Return on Investments, Part1 http:/ / www.appraiser.ru/default.aspx?SectionID=35\&Id=2969, Part. 2 http:/ / www.appraiser.ru/ default.aspx?SectionId=35\&Id=2972, (in Russian).

THE APPRAISAL FOUNDATION, 2006, Uniform Standards of Professional Appraisal Practice and Advisory Opinions, Edition 2006.

WiNNICK L., 1952, Long-run changes in the Valuation of Real Estate by Gross Rents, The Appraisal Journal, October 1952, pp. 484-498.

YISHENG Y.U., 2004, The variation of capitalization rates across submarkets within the same metropolitan area, MIT Thesis Paper, http://dspace.mit.edu/bitstream/handle/1721.1/26731/59759952MIT.pdf?sequence=2. 